\title{
Identifying patterns of care for elderly patients with non-surgically treated stage III non-small cell lung cancer: an analysis of the national cancer database
}

\author{
Eric D Miller ${ }^{1}$, James L Fisher ${ }^{2}$, Karl E Haglund ${ }^{1}$, John C Grecula ${ }^{1}$, Meng Xu-Welliver ${ }^{1}$, Erin M Bertino ${ }^{3}$, Kai He $^{3}$,
} Peter G Shields ${ }^{3}$, David P Carbone ${ }^{3}$, Terence M Williams ${ }^{1}$, Gregory A Otterson ${ }^{3}$ and Jose G Bazan ${ }^{1 *}$

\begin{abstract}
Background: To compare patterns of care for elderly patients versus non-elderly patients with non-surgically treated stage III non-small cell lung cancer (NSCLC) using the National Cancer Database (NCDB). We hypothesize that elderly patients are less likely to receive curative treatments, including concurrent chemoradiation (CCRT), compared to non-elderly patients.

Methods: We identified patients from the NCDB between 2003 and 2014 with non-surgically treated stage III NSCLC. We defined elderly as $\geq 70$ years old and non-elderly $<70$ years old. Treatment categories included: no treatment, palliative treatment (chemotherapy alone, radiation (RT) alone $<59.4$ Gy or chemoradiation (CRT) $<59.4$ Gy), or definitive treatment (RT alone $\geq 59.4$ Gy or CRT $\geq 59.4$ Gy). Differences in treatment between elderly and non-elderly were tested using the $x^{2}$ test.

Results: We identified 57,602 elderly and 55,928 non-elderly patients. More elderly patients received no treatment $(24.5 \%$ vs. $13.2 \%, P<0.0001)$ and the elderly were less likely to receive definitive treatment (48.5\% vs. $56.3 \%, P<0.0001)$. CCRT was delivered in a significantly smaller proportion of elderly vs. non-elderly patients $(66.0 \%$ vs. $78.9 \%, P<0.0001$ in patients treated with definitive intent; $32.0 \%$ vs. $44.5 \%, P<0.0001$ in patients receiving any treatment; and $24.2 \%$ vs. $38.6 \%, P<0.0001$ amongst all patients).

Conclusions: In this large study of patients with non-surgically treated stage III NSCLC, elderly patients were less likely to receive any treatment or treatment with definitive intent compared to the non-elderly. The lack of use of concurrent or sequential chemotherapy in the elderly with stage III NSCLC suggests that the optimal treatment approach for this vulnerable population remains undefined.
\end{abstract}

Keywords: Non-small cell lung cancer, Stage III, Elderly, Patterns of care, Chemoradiation

\section{Background}

Non-small cell lung cancer (NSCLC) is a disease of the elderly with over two-thirds of cases occurring in patients aged $\geq 65$ years and an incidence rate that is $>3$-fold higher in patients $\geq 70$ years compared to patients aged 60-69 and $>10$-fold higher compared to

\footnotetext{
* Correspondence: jose.bazan2@osumc.edu

${ }^{1}$ Department of Radiation Oncology, at the Arthur G. James Cancer Hospital and Richard J. Solove Research Institute, The Ohio State University, 460 W. 10th Avenue, Columbus, OH 43210, USA

Full list of author information is available at the end of the article
}

patients $<60[1,2]$. Nearly one-third of newly diagnosed NSCLC presents as stage III disease [3]. The standard treatment recommendation for unresectable stage III NSCLC on the basis of randomized trials and meta-analyses is concurrent chemoradiation (CCRT) [4]. The applicability of this treatment recommendation to elderly patients has been questioned due to the limited number of elderly individuals treated on stage III NSCLC clinical trials [5-7].

While the data supporting CCRT for stage III NSCLC in the elderly are mixed [8-11], we recently demonstrated

(c) The Author(s). 2018 Open Access This article is distributed under the terms of the Creative Commons Attribution 4.0 International License (http://creativecommons.org/licenses/by/4.0/), which permits unrestricted use, distribution, and 
that chemoradiation (CRT), both CCRT and sequential chemoradiation (SCRT), is associated with improved outcomes when compared to radiation alone using the National Cancer Data Base (NCDB) [12]. Furthermore, results from the phase III JCOG0301 trial which enrolled elderly patients with unresectable stage III NSCLC, demonstrated improved survival with chemoradiation compared to radiation therapy alone [13]. This supports the notion that the addition of chemotherapy to radiation results in superior survival compared to radiation alone in the elderly population. In the current study, we set to fully characterize and compare patterns of care in elderly ( $\geq 70$ years old) vs. non-elderly ( $<70$ years old $)$ patients with non-surgically treated stage III NSCLC. We hypothesized that elderly patients were less likely to receive any treatment or curative intent treatment compared to younger patients.

\section{Methods}

The NCDB, a combined effort of the Commission on Cancer (CoC) of the American College of Surgeons and the American Cancer Society, is a nationwide hospital-based database that contains de-identified hospital registry data from more than 1,500 accredited facilities and represents more than $70 \%$ of newly diagnosed cancer cases in the United States [14]. The NCDB collects data on patient demographics and comorbidities, tumor characteristics and staging details, primary therapies administered, and OS. The CoC's NCDB and the hospitals participating in the CoC NCDB are the source of the de-identified data and have not verified and are not responsible for the statistical validity of the data analysis nor the conclusions presented in this study.

\section{Patient selection}

Patients diagnosed with stage III NSCLC from 2003 to 2014 were collected from the NCDB participant user file with additional inclusion and exclusion criteria summarized in Fig. 1. We defined elderly as patients $\geq 70$ years old, as used previously in numerous studies $[11,13,15-$ 17] and non-elderly as $<70$ years old. The transition to the American Joint Committee on Cancer (AJCC) 7th edition occurred in 2010, consequently, our patient cohort consisted of a mix of patients staged using the AJCC 6th and 7th editions. We have previously characterized the patient selection criteria [12] with the exception that in this analysis, patients that received $>74$ Gy were excluded.

\section{Treatment definitions}

Treatment with palliative intent was defined as treatment with chemotherapy alone, RT alone to doses $<59.4$ Gy but $>8$ Gy, or a combination of chemotherapy and RT delivered either sequentially or concurrently where the delivered RT dose was $<59.4$ Gy but $>8$ Gy. We used 59.4 Gy (as opposed to strictly $\geq 60 \mathrm{~Gy}$ ) as our cutpoint for definitive treatment based on the dose used by the Hoosier Oncology Group evaluating consolidation docetaxel after definitive chemoradiation for inoperable stage III NSCLC [18]. Patients were considered to have received concurrent CRT if chemotherapy was delivered within 30 days of the initiation of RT while sequential CRT was defined as chemotherapy delivered $>30$ days within the initiation of RT as defined in prior studies $[12,19]$.

\section{Study variables}

We dichotomized the following baseline covariates: gender (male vs. female), race (white vs. non-white), median income $(\geq \$ 48,000$ vs. $<\$ 48,000)$, primary insurance payor (private vs. non-private), county location (metropolitan vs. urban/rural), facility type (academic vs. community/comprehensive community/integrated network programs), and clinical stage group (IIIB vs. IIIA). The Charlson-Deyo score, a measure of comorbidity was dichotomized as 0 (no comorbities) or 1 ( $\geq 1$ comorbidity). Distance to the nearest facility was analyzed as a continuous variable.

\section{Statistical methods}

The primary objective of this study was to evaluate patterns of care in elderly vs. non-elderly patients with stage III NSCLC not treated surgically. Differences in treatment modality between elderly and non-elderly patients were tested using the $x^{2}$ test. Logistic regression was used to identify predictors of: 1) No treatment vs. treatment, 2) palliative treatment vs. definitive treatment, and 3) RT alone vs. CRT. Variables with $P \leq 0.10$ on univariate analysis were included in the multivariate model. All statistical analyses were performed using SAS, version 9.4 (SAS Institute Inc., Cary, NC).

\section{Results}

\section{Baseline characteristics}

We identified 57,602 elderly patients and 55,928 nonelderly patients that met the study criteria (Fig. 1). Patient characteristics for the entire cohort are shown in Table 1 . Overall, elderly patients were more likely to be female, white, live in metropolitan areas, have non-private insurance, have stage IIIA disease, and have more comorbidities compared to the non-elderly. Elderly patients had lower income and were less likely to be treated in academic centers.

\section{Patterns of care}

Figure 2a provides an overall summary of treatments administered to the patients included in this study. When including the 57,602 elderly and 55,928 non-elderly 


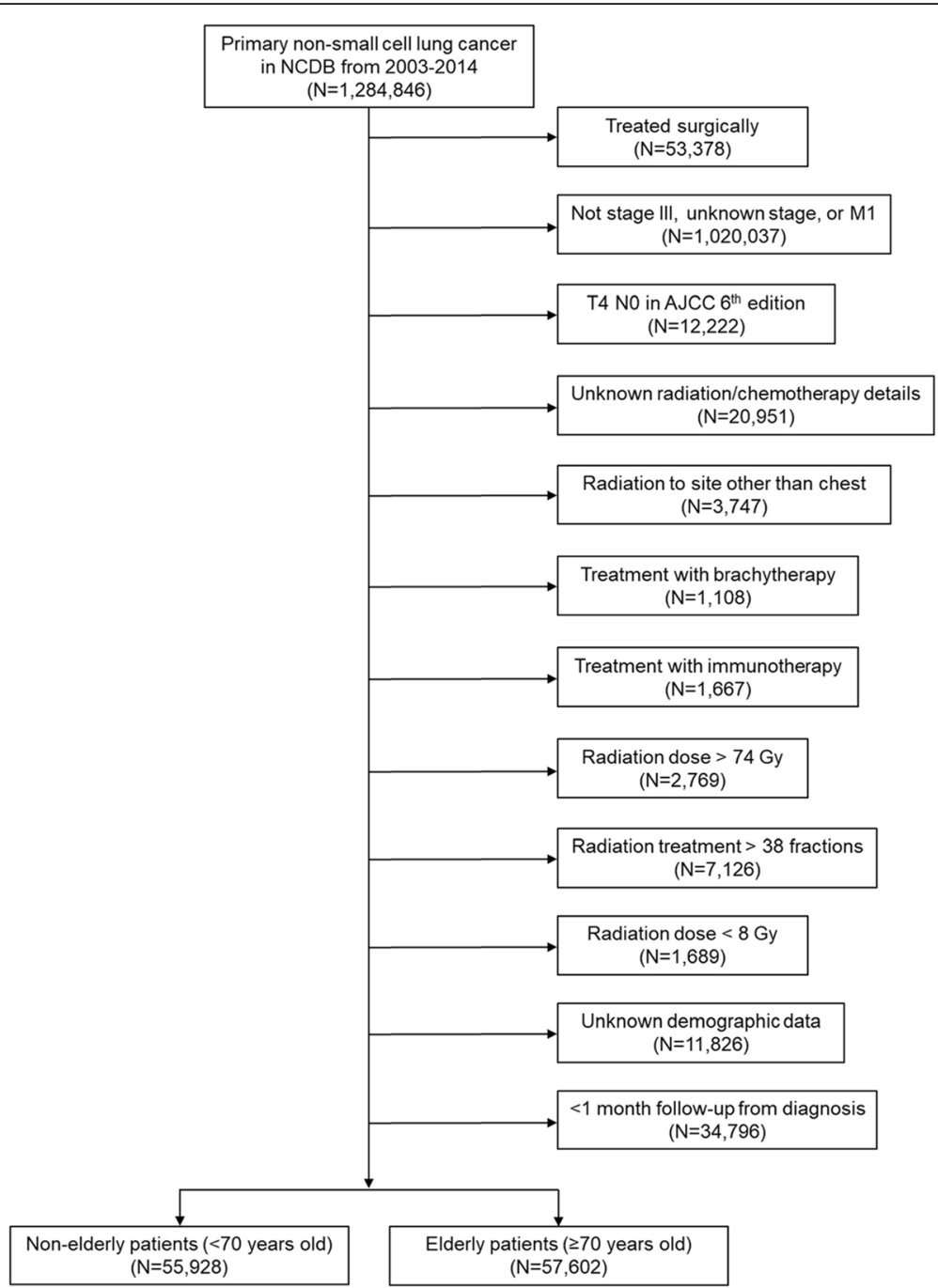

Fig. 1 Study flow diagram for analytic cohorts. Abbreviation: NCDB, National Cancer Database

patients, a significantly higher proportion of elderly patients received no treatment $(24.5 \%$ vs. $13.2 \%, P<0.0001)$, palliative treatment $(38.9 \%$ vs. $37.9 \%, P=0.0005)$, and definitive radiation therapy alone $(7.7 \%$ vs. $3.2 \%, P<0.0001)$, and a lower proportion received definitive chemoradiation (28.9\% vs. $45.6 \%, P<0.0001)$.

\section{No treatment vs. treatment}

As seen in Fig. 2a, the elderly had a significantly higher proportion of patients that did not receive any treatment compared to the non-elderly: $24.5 \%$ vs. $13.2 \%(P<0.0001)$. On multivariate analysis (Table 2 ), elderly patients were nearly twice as likely to not receive treatment: $\mathrm{OR}=1.97$ (95\% CI 1.90-2.03, $P<0.0001)$. Other factors associated with increased odds of not receiving treatment included patients with any comorbidities ( $\mathrm{OR}=1.33,95 \%$ CI 1.29-1.37), female patients $(\mathrm{OR}=1.13,95 \% \mathrm{CI} 1.09-1.16)$, and patients with higher income $(\mathrm{OR}=1.06,95 \% \mathrm{CI} 1.03-1.10)$.

\section{Palliative treatment vs. definitive treatment}

Amongst the 43,512 elderly and 48,555 non-elderly patients that received any treatment, Fig. $2 \mathrm{~b}$ shows that the elderly were most likely to be treated with palliative intent: $51.5 \%$ vs. $43.7 \%(P<0.0001)$. On multivariate analysis (Table 3 ), this translated into the elderly having a $38 \%$ increased odds of receiving palliative treatment $(\mathrm{OR}=1.38,95 \%$ 1.34-1.42). Stage IIIB (vs. stage IIIA) was associated with the highest odds of receiving palliative vs. definitive treatment $(\mathrm{OR}=1.80$, 95\% CI $1.75-$ 1.84). Other factors associated with higher odds of receiving palliative treatment included female gender, metropolitan county location, and more comorbidities 
Table 1 Patient characteristics in the elderly and non-elderly cohorts

\begin{tabular}{|c|c|c|c|}
\hline Characteristic & $\begin{array}{l}\text { Elderly } \\
(N=57602)\end{array}$ & $\begin{array}{l}\text { Non-Elderly } \\
(N=55928)\end{array}$ & $P$-value \\
\hline Age, mean (SD), years & $77.5(5.3)$ & $60.2(7.0)$ & N/A \\
\hline Gender & & & $<0.0001$ \\
\hline Female & $26217(45.5)$ & $24050(43.0)$ & \\
\hline Male & $31385(54.5)$ & $31878(57.0)$ & \\
\hline Race & & & $<0.0001$ \\
\hline White & $50439(87.6)$ & $45708(81.7)$ & \\
\hline Non-white & $7163(12.4)$ & $10220(18.3)$ & \\
\hline Charlson-Deyo score & & & $<0.0001$ \\
\hline 0 & $33237(57.7)$ & $35177(62.9)$ & \\
\hline $1-2$ & $24365(42.3)$ & $20751(37.1)$ & \\
\hline Median income & & & $<0.0001$ \\
\hline$\geq \$ 48,000$ & $26397(45.8)$ & $28604(51.1)$ & \\
\hline$<\$ 48,000$ & $31205(54.2)$ & $27324(48.9)$ & \\
\hline Primary payor & & & $<0.0001$ \\
\hline Private & $5562(9.7)$ & $25033(44.8)$ & \\
\hline Non-private & $52040(90.3)$ & $30895(55.2)$ & \\
\hline County Location & & & $<0.0001$ \\
\hline Metropolitan & $47064(81.7)$ & $44545(79.7)$ & \\
\hline Non-metropolitan & $10538(18.3)$ & $11383(20.3)$ & \\
\hline $\begin{array}{l}\text { Distance to closest } \\
\text { facility, mean (SD), miles }\end{array}$ & $20.2(78.4)$ & $23.0(81.0)$ & $<0.0001$ \\
\hline Facility type & & & $<0.0001$ \\
\hline Academic & $14682(25.5)$ & $16929(30.3)$ & \\
\hline Non-academic & $42920(74.5)$ & $38999(69.7)$ & \\
\hline Clinical stage group & & & $<0.0001$ \\
\hline$\| I I A$ & $31973(55.5)$ & $27974(50.0)$ & \\
\hline$\| \mathrm{II}$ & $25629(44.5)$ & $27954(50.0)$ & \\
\hline
\end{tabular}

Abbreviation: $S D$ standard deviation

while white patients and those with private insurance were more likely to receive definitive treatment.

For the patients treated with palliative intent who received radiation therapy, the radiation doses were further binned based on dose. Of the 22,726 patients who received radiation as part of their palliative treatment, 6298 (27.7\%) received a dose $>8$ and $\leq 30 \mathrm{~Gy}, 7,708$ (33.9\%) received $>30$ and $\leq 45 \mathrm{~Gy}$, and 8,720 (38.4\%) received $>45$ and $<59.4$ Gy. The median biological effective dose (using $\alpha / \beta=10$ ) based on the linear quadratic formula for this group was 63.4 $\mathrm{Gy}_{10}\left(\mathrm{IQR}=59.5-67.6 \mathrm{~Gy}_{10}\right)$ and the median fraction size was $2 \mathrm{~Gy}$ (IQR, 1.8-2.25 Gy).

\section{Definitive treatment: $R T$ alone vs. CRT}

Within the group of 21,119 elderly and 27,341 non-elderly patients treated with definitive therapy, a significantly higher proportion of the elderly were treated with RT alone $(10.2 \%$ vs. $3.7 \%, P<0.0001$, Fig. $2 b)$, which resulted in a $>3$-fold increase in the likelihood of receiving RT alone for the elderly $(\mathrm{OR}=3.30,95 \% \mathrm{CI} 3.10-3.51)$ on multivariate analysis (Table 4). Patients with private insurance were $32 \%$ less likely to receive $\mathrm{RT}$ alone $(\mathrm{OR}=0.68$, 95\% CI 0.63-0.73). Other factors resulted in modest increases (more comorbidities, higher income) or decreases (stage IIIB, further distance to treatment facility) in the likelihood of patients receiving RT alone.

Analyzing only patients that received CRT $(N=16,668$ elderly and 25,552 non-elderly), a higher proportion of elderly patients received SCRT compared to the non-elderly $(16.4 \%$ vs. $15.5 \%, P=0.016)$ as seen in Fig. 2c. In total, 13,940 elderly patients and 21,594 non-elderly patients received CCRT. The respective differences in proportions of elderly patients vs. non-elderly patients that received CCRT when looking at the entire population, only patients that received treatment, and only patients that received definitive treatment were: $24.2 \%$ vs. $38.6 \%(P<0.0001) ; 32.0 \%$ vs. $44.5 \%(P<0.0001) ; 66.0 \%$ vs. $78.9 \%(P<0.0001)$.

When CRT was delivered, most patients received a multi-agent chemotherapy vs. single-agent chemotherapy regimen. However, a lower proportion of elderly patients received multi-agent chemotherapy compared to the non-elderly: $91.8 \%$ vs. $95.3 \%$ in the CCRT patients $(P<0.0001)$, and $91.1 \%$ vs. $96.1 \%(P<0.0001)$ in the SCRT patients. For the 48,460 patients treated with definitive intent, 29,233 (60.3\%) received a dose $\geq 59.4$ Gy and $<66$ Gy, 13,821 (28.5\%) received $\geq 66$ Gy and $<70$ Gy, and $5,406(11.2 \%)$ received doses $\geq 70 \mathrm{~Gy}$.

Given the wide range of palliative radiation therapy doses used, we performed a sensitivity analysis where the 8,720 patients who received $>45$ and $<59.4$ Gy were included as part of the definitive rather than palliative treatment group. The results of this analysis are shown in Additional file 1: Figure S1. The overall results remained the same with the elderly more likely to not receive treatment $(24.5 \%$ vs. $13.2 \%, P<0.0001)$, more likely to receive a palliative treatment $(31.3 \%$ vs. $30.1 \%, P<0.0001)$, and more likely to receive definitive RT alone $(10.7 \%$ vs. $4.4 \%, P<0.0001)$ than definitive CRT $(33.5 \%$ vs. $52.3 \%, P<0.0001)$ when compared to non-elderly patients.

\section{Discussion}

In summary, we found substantial disparities in the management of non-surgically treated stage III NSCLC based on age ( $\geq 70$ years old vs. $<70$ years old) in the largest study to date. Compared to non-elderly patients, elderly patients were twice as likely to not receive any treatment and 1.4 times more likely to receive palliative treatment when treatment was delivered. When definitive treatment was delivered, the elderly were $>3$-fold more likely to receive radiation therapy alone as opposed to CRT. Of note, in the subset of patients treated with definitive CRT, there 


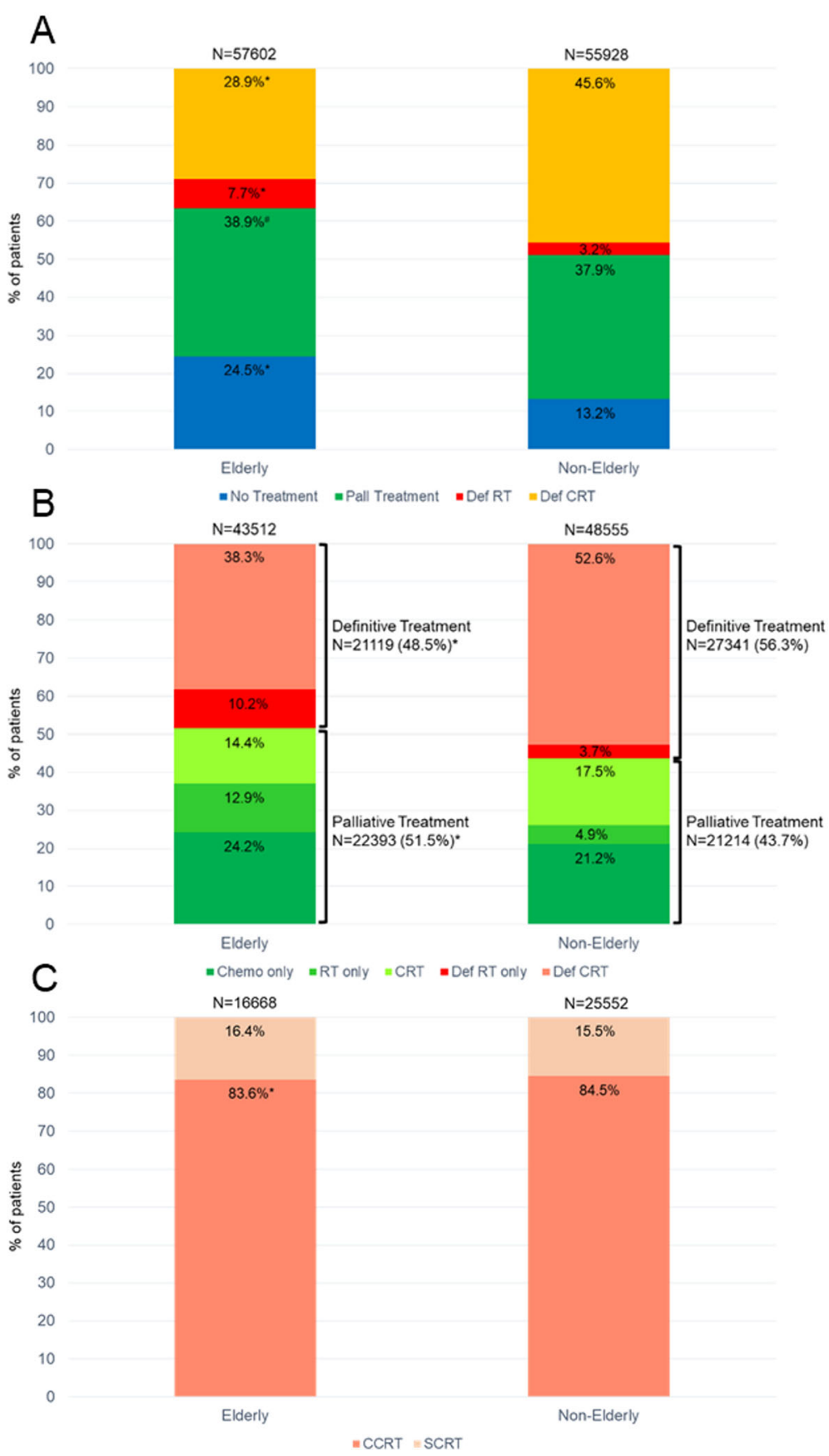

Fig. 2 Bar graphs representing key comparisons of treatment patterns in the elderly vs. non-elderly patients: (a) Proportion of all patients included in the study who received no treatment, palliative (Pall) treatment, definitive radiation therapy (Def RT), and definitive chemoradiation (Def CRT), ${ }^{*} P<0.0001, \# P=0.0005$. (b) Proportion of patients receiving any treatment further subdivided into definitive (Def RT only - definitive radiation therapy alone, Def CRT - definitive chemoradiation including sequential and concurrent chemoradiation), and palliative treatments (Chemo only - chemotherapy alone, RT only - palliative radiation therapy alone, CRT - palliative chemoradiation), ${ }^{*} P<0.0001$. (c) Proportion of patients receiving definitive chemoradiation who received sequential (SCRT) and concurrent (CCRT) chemoradiation, ${ }^{*} P=0.016$

was little absolute difference observed between the elderly and non-elderly in those that received SCRT (16.4\% versus $15.5 \%)$. While this $0.9 \%$ difference was statistically significant, a larger absolute difference in the SCRT rates between elderly and non-elderly patients may have been expected. However, the smaller difference in SCRT rates is undoubtedly impacted by the overall key finding of our study which is that a significantly smaller proportion of elderly patients receive definitive CRT compared to the non-elderly. 
Table 2 Logistic regression analysis of factors associated with not receiving treatment $(O R>1$ means first factor is associated with a higher odds of not receiving treatment)

\begin{tabular}{|c|c|c|c|c|c|c|}
\hline \multirow{2}{*}{$\begin{array}{l}\text { No Treatment vs. Treatment } \\
\text { Variable }\end{array}$} & \multicolumn{3}{|c|}{ Univariate Analysis } & \multicolumn{3}{|c|}{ Multivariate Analysis } \\
\hline & $\mathrm{OR}$ & $95 \% \mathrm{Cl}$ & $P$-value & $\overline{O R}$ & $95 \% \mathrm{Cl}$ & $P$-value \\
\hline Elderly vs. Non-Elderly & 2.13 & $2.07-2.20$ & $<0.0001$ & 1.97 & $1.90-2.03$ & $<0.0001$ \\
\hline Female vs. male & 1.13 & $1.10-1.17$ & $<0.0001$ & 1.13 & $1.09-1.16$ & $<0.0001$ \\
\hline White vs. non-white & 0.91 & $0.87-0.95$ & $<0.0001$ & 0.84 & $0.80-0.87$ & $<0.0001$ \\
\hline Academic vs. non-academic & 0.93 & $0.90-0.96$ & $<0.0001$ & 0.98 & $0.94-1.01$ & 0.1751 \\
\hline Private vs. non-private insurance & 0.56 & $0.54-0.58$ & $<0.0001$ & 0.77 & $0.75-0.81$ & $<0.0001$ \\
\hline Median income $(\geq \$ 48,000$ vs. $<\$ 48,000)$ & 1.07 & $1.04-1.10$ & $<0.0001$ & 1.06 & $1.03-1.10$ & 0.0002 \\
\hline County location (Metropolitan vs. non-metropolitan) & 1.03 & $0.99-1.07$ & 0.1080 & - & - & - \\
\hline Clinical stage IIIB vs. stage IIIA & 0.97 & $0.94-1.00$ & 0.0406 & 1.02 & $0.99-1.05$ & 0.2312 \\
\hline Distance to closest facility ${ }^{a}$ & 0.98 & $0.97-0.99$ & 0.0006 & 1.01 & $1.00-1.02$ & 0.1479 \\
\hline Charlson-Deyo score (1 vs. 0) & 1.40 & $1.35-1.44$ & $<0.0001$ & 1.33 & $1.29-1.37$ & $<0.0001$ \\
\hline
\end{tabular}

Abbreviations: $\mathrm{Cl}$ confidence interval, $\mathrm{OR}$ odds ratio; ${ }^{\mathrm{a}} \log$ (distance) was used for analysis

Consistent with other reports, a large proportion of elderly patients with locally advanced NSCLC did not receive any type of treatment $[8,19]$. In our patient cohort, $24.5 \%$ of elderly patients did not receive treatment which was significantly higher than the proportion of patients $<70$ years old $(13.2 \%)$. In a SEER-Medicare analysis of 6,325 patients $>65$ years old with locally advanced NSCLC, $26.5 \%$ of patients did not receive any cancer directed treatment [8]. Wang et al. utilized the Veterans Affairs Central Cancer Registry to evaluate the administration of guideline recommended treatment in patients $\geq 65$ years old with NSCLC [19]. Older patients with no comorbidities were administered guideline recommended treatment less often than younger patients with severe comorbidities. Similarly, we found that when treatment was administered, fewer than one-third of the elderly patients received definitive CRT compared to nearly half of the non-elderly patients.
Recently, Davidoff et al. used the NCDB to study patterns of care and outcomes in 12,641 octagenarians and nonagenerians with stage III NSCLC [8]. These patients were categorized into one of 3 groups: no treatment, RT alone ( $\geq 45 \mathrm{~Gy}$ ), or CRT. In this subset of elderly patients with advanced age, more than $60 \%$ did not receive any treatment at all. While the definition of treatment was not exactly the same as the one used in our study, we both found similar factors associated with patients not receiving treatment: increasing age, more comorbidities, non-white race, and female sex.

In a population-based dataset from the Netherlands Cancer Registry, Driessen et al. examined treatment patterns and survival in older patients (65-74 years old, $N=3,876$ and $\geq 75$ years old, $N=3,163$ ) with stage III NSCLC from 2009 to 2013 [20]. In this dataset, $17 \%$ of patients aged $65-74$ years old and $39 \%$ of patients aged $\geq 75$ years did not receive any treatment for a total of

Table 3 Logistic regression analysis of factors associated with palliative treatment amongst patients that received any treatment $(\mathrm{OR}>1$ means that the first factor is associated with higher odds of receiving palliative treatment)

\begin{tabular}{|c|c|c|c|c|c|c|}
\hline \multirow{2}{*}{$\begin{array}{l}\text { Palliative vs. Definitive Treatment } \\
\text { Variable }\end{array}$} & \multicolumn{3}{|c|}{ Univariate Analysis } & \multicolumn{3}{|c|}{ Multivariate Analysis } \\
\hline & $\mathrm{OR}$ & $95 \% \mathrm{Cl}$ & $P$-value & $\mathrm{OR}$ & $95 \% \mathrm{Cl}$ & $P$-value \\
\hline Elderly vs. Non-Elderly & 1.37 & $1.33-1.40$ & $<0.0001$ & 1.38 & $1.34-1.42$ & $<0.0001$ \\
\hline Female vs. male & 1.10 & $1.07-1.13$ & $<0.0001$ & 1.11 & $1.08-1.14$ & $<0.0001$ \\
\hline White vs. non-white & 0.93 & $0.90-0.97$ & 0.0001 & 0.91 & $0.88-0.95$ & $<0.0001$ \\
\hline Academic vs. non-academic & 1.01 & $0.98-1.04$ & 0.4758 & - & - & - \\
\hline Private vs. non-private insurance & 0.83 & $0.80-0.85$ & $<0.0001$ & 0.92 & $0.89-0.95$ & $<0.0001$ \\
\hline Median income $(\geq \$ 48,000$ vs. $<\$ 48,000)$ & 0.95 & $0.93-0.98$ & 0.0002 & 0.98 & $0.95-1.00$ & 0.0762 \\
\hline County location (Metropolitan vs. non-metropolitan) & 1.12 & $1.08-1.15$ & $<0.0001$ & 1.11 & $1.07-1.16$ & $<0.0001$ \\
\hline Clinical stage IIIB vs. stage IIIA & 1.73 & $1.69-1.78$ & $<0.0001$ & 1.80 & $1.75-1.84$ & $<0.0001$ \\
\hline Distance to closest facility ${ }^{a}$ & 0.98 & $0.97-0.99$ & 0.0006 & 1.01 & $1.00-1.02$ & 0.0598 \\
\hline Charlson-Deyo score (1 vs. 0) & 1.19 & $1.16-1.23$ & $<0.0001$ & 1.20 & $1.17-1.23$ & $<0.0001$ \\
\hline
\end{tabular}

Abbreviations: $\mathrm{Cl}$ confidence interval, $\mathrm{OR}$ odds ratio; ${ }^{\mathrm{a}} \log ($ distance) was used for analysis 
Table 4 Logistic regression analysis of receiving radiation therapy alone versus chemoradiation in patients that received definitive treatment $(O R>1$ means that first factor is associated with higher odds of radiation therapy alone)

\begin{tabular}{|c|c|c|c|c|c|c|}
\hline \multirow{2}{*}{$\begin{array}{l}\text { Radiation Therapy Alone vs. Chemoradiation } \\
\text { Variable }\end{array}$} & \multicolumn{3}{|c|}{ Univariate Analysis } & \multicolumn{3}{|c|}{ Multivariate Analysis } \\
\hline & OR & $95 \% \mathrm{Cl}$ & $P$-value & OR & $95 \% \mathrm{Cl}$ & $P$-value \\
\hline Elderly vs. Non-Elderly & 3.81 & $3.30-4.04$ & $<0.0001$ & 3.30 & $3.07-3.51$ & $<0.0001$ \\
\hline Female vs. male & 1.05 & $0.99-1.11$ & 0.0840 & 1.04 & $0.99-1.10$ & 0.1445 \\
\hline White vs. non-white & 0.96 & $0.89-1.03$ & 0.2684 & - & - & - \\
\hline Academic vs. non-academic & 0.91 & $0.86-0.97$ & 0.0024 & 1.02 & $0.96-1.09$ & 0.5296 \\
\hline Private vs. non-private insurance & 0.38 & $0.35-0.41$ & $<0.0001$ & 0.68 & $0.63-0.73$ & $<0.0001$ \\
\hline Median income $(\geq \$ 48,000$ vs. $<\$ 48,000)$ & 1.18 & $1.12-1.25$ & 0.0002 & 1.26 & $1.19-1.33$ & $<0.0001$ \\
\hline County location (Metropolitan vs. non-metropolitan) & 1.07 & $1.00-1.15$ & 0.0473 & 1.05 & $0.97-1.14$ & 0.2267 \\
\hline Clinical stage IIIB vs. stage IIIA & 0.73 & $0.69-0.77$ & $<0.0001$ & 0.82 & $0.78-0.87$ & $<0.0001$ \\
\hline Distance to closest facility ${ }^{a}$ & 0.90 & $0.88-0.92$ & $<0.0001$ & 0.93 & $0.91-0.95$ & $<0.0001$ \\
\hline Charlson-Deyo score (1 vs. 0) & 1.31 & $1.24-1.38$ & $<0.0001$ & 1.22 & $1.15-1.29$ & $<0.0001$ \\
\hline
\end{tabular}

Abbreviations: $\mathrm{Cl}$ confidence interval, $\mathrm{OR}$ odds ratio; ${ }^{\mathrm{a}} \log ($ distance) was used for analysis

approximately $27 \%$ of patients $\geq 65$ years old not receiving any treatment. This rate is remarkably similar to the $24 \%$ of patients $\geq 70$ years old in the United States NCDB that did not receive any treatment.

The same group has also examined changes in treatment patterns for all stages of NSCLC in patients $<70$ years old and $\geq 70$ years old from 1990 to 2014 [21]. In both younger patients and older patients, the proportion that do not receive treatment has declined over time from $18 \%(1990-1994)$ to $10 \%(2010-2014)$ in younger patients and from $32 \%(1990-1994)$ to $29 \%$ (2010-2014) in the older patients. In the most recent cohort (2010-2014), the proportion of younger patients receiving CRT was $48 \%$ which is comparable to the $46 \%$ of younger patients in our study that received CRT. Similarly, $27 \%$ of elderly patients received CRT in the Netherlands Cancer Registry compared to $29 \%$ in our study.

These cohort studies demonstrate that elderly patients with stage III NSCLC are less likely to receive standard curative treatments compared to younger patients. CRT for stage III NSCLC, particularly CCRT, can result in severe acute morbidities including esophagitis, hematologic toxicity, and pneumonitis, particularly in elderly patients [4, 9-11, 13, 22-27]. Furthermore, CCRT is associated with $\sim 2 \%$ risk of treatment-related acute mortality in contemporary phase III trials $[28,29]$. The morbidity/mortality concerns most likely factor into the treatment decision for elderly patients. In a systematic review of the use of a comprehensive geriatric assessment (CGA) tool in elderly patients with NSCLC, Schulkes et al. found that the CGA can help detect several health concerns not reflected by the patient's Eastern Cooperative Oncology Group performance status and that certain CGA domains are predictive of mortality and treatment completion [30]. In order to help identify elderly patients that are at particularly high risk of treatment-related morbidity/mortality, use of a CGA is now endorsed by the National Cancer Network, the International Society for Geriatric Oncology, and the European Organization for the Research and Treatment of Cancer [31-33]. The CGA has not been a component of previous randomized studies in stage III NSCLC, but it should be incorporated in elderly patients treated on future trials to help validate its usefulness.

In addition to assessment tools that may help identify patients at higher risk of toxicity, there have also been demonstrable improvements in radiation therapy delivery that may help reduce toxicity and potentially improve survival in patients receiving CCRT for stage III NSCLC. In an NCDB analysis of patients with stage III NSCLC treated between 2003 and 2005, Sher et al. demonstrated that conformal radiotherapy techniques using computed-tomography (CT) based planning, including 3D conformal radiation therapy (3DCRT) and intensity-modulated radiation therapy (IMRT), resulted in a statistically significant $3 \%$ absolute increase in 3-year and 5-year survival rates compared with conventional 2D radiation therapy [34]. Subsequently, Koshy et al. compared survival in patients with stage III NSCLC treated with IMRT vs. non-IMRT techniques from 2003 to 2011 in the NCDB. In this analysis, patients treated with IMRT had an $11 \%$ relative reduction in the risk of death, translating into an improved median survival time of 20 months vs. 18.2 months [35]. Furthermore, IMRT resulted in a lower incidence of radiation therapy treatment interruptions. With regards to toxicity, a secondary analysis of Radiation Therapy Oncology Group 0617, a randomized study of CCRT to 60 Gy vs. 74 Gy in unresectable stage III NSCLC, demonstrated that IMRT was associated with lower rates of severe radiation pneumonitis and resulted in overall lower cardiac doses when compared to patients treated with 3DCRT [36]. 
Taken together, these three studies conducted in a relatively modern treatment era suggest that CT based planning using IMRT has led to reduced morbidity and mortality compared to outdated radiation techniques - therefore, elderly patients treated with the modern radiation techniques currently available may be able to better tolerate aggressive treatment approaches such as CCRT.

Limitations of this study include its retrospective nature and the lack of toxicity data, which is not captured by the NCDB. In addition, while the NCDB captures the Charlson-Deyo score, it does not include other critical data elements such as performance status, smoking history, extent of disease radiographically, and patient preferences, all of which factor into the treatment-decision making process. Studies that use the NCDB to compare survival amongst various treatment groups are often appropriately criticized because despite the large sample size, it can be argued that the non-randomized retrospective nature of these studies actually amplifies selection bias and leads to equally amplified differences in survival between treatment groups. However, in this study, we present a patterns-of-care analysis, and not a comparison of survival amongst various treatment groups. In addition, we may be criticized for the decision to use $\geq 59.4$ Gy as the radiation dose that defines definitive intent. Alternative fractionation schedules with doses that approach an equivalent dose of near $60 \mathrm{~Gy}$ in 30 fractions (continuous hyperfractionated accelerated radiation therapy, hypofractionated radiation ( $\geq 3 \mathrm{~Gy} /$ fraction) schedules to 50-60 Gy total dose, etc.) are the subject of much discussion for patients that cannot tolerate concurrent chemotherapy. In order to account for the possibility that the patients classified as having received palliative radiation therapy to doses of $>45 \mathrm{~Gy}$ but <59.4 Gy may have received definitive treatment, we performed a sensitivity analysis in which all of these patients were classified as having received definitive radiation therapy. Our results did not change, which solidified our decision for 59.4 Gy as the cutoff for distinguishing definitive vs. palliative radiation therapy. Ultimately, shorter hypofractionated schedules may be the best approach for elderly patients, and we eagerly await the results of a current randomized phase III trial testing 60 Gy in 15 fractions to 60 Gy in 30 fractions [37].

Despite these limitations, our study has notable strengths. First, we present a detailed patterns of care analysis that characterizes the treatment of $\sim 70 \%$ of every non-surgically treated stage III NSCLC in the United States. In effect, we have described the actual treatment delivered to the vast majority of patients in academic and non-academic centers in the U.S. Moreover, our analysis includes a rigorous assessment of how each patient was treated, especially with regard to radiation dose and target volume, which are details that are not available in the SEER database. To date, this is the largest (57,602 elderly patients and 55,928 non-elderly patients) and most comprehensive analysis highlighting the disparities in patterns of care in elderly vs. non-elderly patients with non-surgically treated stage III NSCLC. Given the recent results of the PACIFIC trial, which showed a progression-free survival benefit for patients with locally advanced, unresectable stage III NSCLC without disease progression after chemoradiation, it will be interesting to see how the use of immunotherapy impacts patterns of care in the elderly and non-elderly in the next $5-10$ years [38].

\section{Conclusions}

We found that elderly patients with non-surgically treated stage III NSCLC are less likely to receive any treatment, definitive treatment, and CRT compared to non-elderly patients. As a whole, standard of care CCRT was administered to $<25 \%$ of all elderly patients. Even when a definitive treatment course was delivered, more than $20 \%$ of elderly patients received RT alone. The lack of use of concurrent or sequential chemotherapy in the elderly with stage III NSCLC suggests that the optimal treatment approach for this vulnerable population remains undefined.

\section{Additional file}

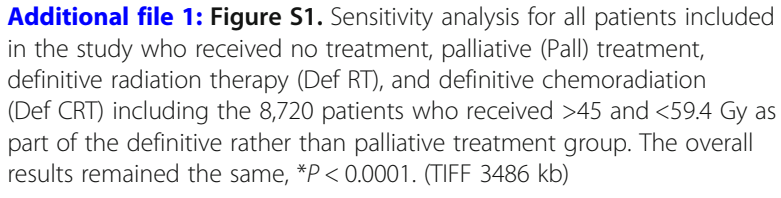

Additional file 1: Figure S1. Sensitivity analysis for all patients included in the study who received no treatment, palliative (Pall) treatment, definitive radiation therapy (Def $\mathrm{R} T$ ), and definitive chemoradiation (Def CRT) including the 8,720 patients who received $>45$ and $<59.4$ Gy as part of the definitive rather than palliative treatment group. The overall results remained the same, ${ }^{*} P<0.0001$. (TIFF $3486 \mathrm{~kb}$ )

\section{Abbreviations \\ 3DCRT: 3D conformal radiation therapy; AJCC: American joint committee on cancer; CCRT: Concurrent chemoradiation; CGA: Comprehensive geriatric assessment; COC: Commission on cancer; CRT: Chemoradiation; \\ CT: Computed-tomography; IGRT: Image-guided radiation therapy; IMRT: Intensity-modulated radiation therapy; NCDB: National cancer database; NSCLC: Non-small cell lung cancer; RT: Radiation therapy; SCRT: Sequential chemoradiation}

\section{Funding}

This publication was supported in part by the National Institutes of Health, [Grant Number P30 CA16058].

\section{Availability of data and materials}

The data that support the findings of this study are available from the National Cancer Database, but restrictions apply to the availability of these data, which were used under license for the current study, and so are not publicly available.

\section{Authors' contributions}

All authors were involved in the conception and design of the study, analysis and interpretation, were involved in drafting of the manuscript, and have given final approval of the manuscript; EDM and JGB acquired the datasets.

\section{Ethics approval and consent to participate}

The NCDB is de-identified in accordance with The Health Insurance Portability and Accountability Act. As the data was considered not to be regulated human subjects research at Ohio State University, review by the institutional review board was deemed unnecessary. 


\section{Consent for publication}

Not applicable.

\section{Competing interests}

The authors declare that they have no competing interests.

\section{Publisher's Note}

Springer Nature remains neutral with regard to jurisdictional claims in published maps and institutional affiliations.

\section{Author details}

'Department of Radiation Oncology, at the Arthur G. James Cancer Hospital and Richard J. Solove Research Institute, The Ohio State University, 460 W. 10th Avenue, Columbus, OH 43210, USA. ${ }^{2}$ College of Public Health, at the Arthur G. James Cancer Hospital and Richard J. Solove Research Institute, The Ohio State University Comprehensive Cancer Center, Columbus, OH, USA ${ }^{3}$ Department of Internal Medicine, Division of Medical Oncology, at the Arthur G. James Cancer Hospital and Richard J. Solove Research Institute, The Ohio State University Comprehensive Cancer Center, Columbus, OH, USA

\section{Received: 16 August 2018 Accepted: 26 September 2018}

\section{Published online: 05 October 2018}

\section{References}

1. Howlader NNA, Krapcho M, Miller D, et al. SEER Cancer Statistics Review, 1975-2014. Bethesda: National Cancer Institute. http://seer.cancer.gov/csr/ 1975_2014/. Accessed 25 Mar 2018.

2. Siegel RL, Miller KD, Jemal A. Cancer statistics, 2018. CA Cancer J Clin. 2018; 68:7-30.

3. Crino L, Weder W, van Meerbeeck J, et al. Early stage and locally advanced (non-metastatic) non-small-cell lung cancer: ESMO clinical practice guidelines for diagnosis, treatment and follow-up. Ann Oncol. 2010;21(Suppl 5):v103-15.

4. Auperin A, Le Pechoux C, Rolland E, et al. Meta-analysis of concomitant versus sequential radiochemotherapy in locally advanced non-small-cell lung cancer. J Clin Oncol. 2010;28:2181-90.

5. Langer CJ. Neglected and underrepresented subpopulations: elderly and performance status 2 patients with advanced-stage non-small-cell lung cancer. Clin Lung Cancer. 2006;7(Suppl 4):S126-37.

6. Lewis $\mathrm{JH}$, Kilgore ML, Goldman DP, et al. Participation of patients 65 years of age or older in cancer clinical trials. J Clin Oncol. 2003:21:1383-9.

7. Sacher AG, Le LW, Leighl NB, et al. Elderly patients with advanced NSCLC in phase III clinical trials: are the elderly excluded from practice-changing trials in advanced NSCLC? J Thorac Oncol. 2013:8:366-8.

8. Davidoff AJ, Gardner JF, Seal B, et al. Population-based estimates of survival benefit associated with combined modality therapy in elderly patients with locally advanced non-small cell lung cancer. J Thorac Oncol. 2011;6:934-41.

9. Driessen EJ, Bootsma GP, Hendriks LE, et al. Stage III non-small cell lung cancer in the elderly: patient characteristics predictive for tolerance and survival of chemoradiation in daily clinical practice. Radiother Oncol. 2016; 121:26-31

10. Schild SE, Mandrekar SJ, Jatoi A, et al. The value of combined-modality therapy in elderly patients with stage III nonsmall cell lung cancer. Cancer. 2007;110:363-8

11. Stinchcombe TE, Zhang $Y$, Vokes EE, et al. Pooled analysis of individual patient data on concurrent chemoradiotherapy for stage III non-small-cell lung cancer in elderly patients compared with younger patients who participated in US National Cancer Institute cooperative group studies. J Clin Oncol. 2017:35:2885-92.

12. Miller ED, Fisher JL, Haglund KE, et al. The addition of chemotherapy to radiation therapy improves survival in elderly patients with stage III nonsmall cell lung cancer. J Thorac Oncol. 2018;13:426-35.

13. Atagi S, Kawahara M, Yokoyama A, et al. Thoracic radiotherapy with or without daily low-dose carboplatin in elderly patients with non-small-cell lung cancer: a randomised, controlled, phase 3 trial by the Japan Clinical Oncology Group (JCOG0301). Lancet Oncol. 2012:13:671-8.

14. Bilimoria KY, Stewart AK, Winchester DP, et al. The national cancer data base: a powerful initiative to improve cancer care in the United States. Ann Surg Oncol. 2008;15:683-90.

15. Quoix E, Zalcman G, Oster JP, et al. Carboplatin and weekly paclitaxel doublet chemotherapy compared with monotherapy in elderly patients with advanced non-small-cell lung cancer: IFCT-0501 randomised, phase 3 trial. Lancet. 2011:378:1079-88.

16. Gridelli C, Perrone F, Gallo C, et al. Effects of vinorelbine on quality of life and survival of elderly patients with advanced non-small-cell lung cancer. J Natl Cancer Inst. 1999;91:66-72.

17. Ramalingam SS, Dahlberg SE, Langer CJ, et al. Outcomes for elderly, advanced-stage non-small-cell lung cancer patients treated with bevacizumab in combination with carboplatin and paclitaxel: analysis of eastern cooperative oncology group trial 4599. J Clin Oncol. 2008;26:60-5.

18. Hanna N, Neubauer M, Yiannoutsos C, et al. Phase III study of cisplatin, etoposide, and concurrent chest radiation with or without consolidation docetaxel in patients with inoperable stage III non-small-cell lung cancer: the Hoosier Oncology Group and U.S. Oncology. J Clin Oncol. 2008;26: 5755-60.

19. Wang $E H$, Rutter $C E$, Corso CD, et al. Patients selected for definitive concurrent chemoradiation at high-volume facilities achieve improved survival in stage III non-small-cell lung cancer. J Thorac Oncol. 2015:10:937-43.

20. Driessen EJM, Schulkes KJG, Dingemans AC, et al. Patterns of treatment and survival among older patients with stage III non-small cell lung cancer. Lung Cancer. 2018;116:55-61.

21. Driessen EJ, Aarts MJ, Bootsma GP, et al. Trends in treatment and relative survival among non-small cell lung cancer patients in the Netherlands (1990-2014): disparities between younger and older patients. Lung Cancer. 2017;108:198-204

22. Atagi S, Kawahara M, Tamura T, et al. Standard thoracic radiotherapy with or without concurrent daily low-dose carboplatin in elderly patients with locally advanced non-small cell lung cancer: a phase III trial of the Japan Clinical Oncology Group (JCOG9812). Jpn J Clin Oncol. 2005;35:195-201.

23. Ademuyiwa FO, Johnson CS, White AS, et al. Prognostic factors in stage III non-small-cell lung cancer. Clin Lung Cancer. 2007:8:478-82.

24. Rocha Lima CM, Herndon JE 2nd, Kosty M, et al. Therapy choices among older patients with lung carcinoma: an evaluation of two trials of the cancer and leukemia group B. Cancer. 2002;94:181-7.

25. Schild SE, Stella PJ, Geyer SM, et al. The outcome of combined-modality therapy for stage III non-small-cell lung cancer in the elderly. J Clin Oncol. 2003:21:3201-6.

26. Socinski MA, Zhang C, Herndon JE 2nd, et al. Combined modality trials of the cancer and leukemia group B in stage III non-small-cell lung cancer: analysis of factors influencing survival and toxicity. Ann Oncol. 2004;15: 1033-41.

27. Stinchcombe TE, Hodgson L, Herndon JE 2nd, et al. Treatment outcomes of different prognostic groups of patients on cancer and leukemia group B trial 39801: induction chemotherapy followed by chemoradiotherapy compared with chemoradiotherapy alone for unresectable stage III nonsmall cell lung cancer. J Thorac Oncol. 2009:4:1117-25.

28. Bradley JD, Paulus R, Komaki R, et al. Standard-dose versus high-dose conformal radiotherapy with concurrent and consolidation carboplatin plus paclitaxel with or without cetuximab for patients with stage IIIA or IIIB nonsmall-cell lung cancer (RTOG 0617): a randomised, two-by-two factorial phase 3 study. Lancet Oncol. 2015;16:187-99.

29. Curran WJ Jr, Paulus R, Langer CJ, et al. Sequential vs. concurrent chemoradiation for stage III non-small cell lung cancer: randomized phase III trial RTOG 9410. J Natl Cancer Inst. 2011;103:1452-60.

30. Schulkes KJ, Hamaker ME, van den Bos F, et al. Relevance of a geriatric assessment for elderly patients with lung cancer-a systematic review. Clin Lung Cancer. 2016;17:341-9 e343.

31. Trovo M, Giaj-Levra N, Furlan C, et al. Stereotactic body radiation therapy and intensity modulated radiation therapy induce different plasmatic cytokine changes in non-small cell lung cancer patients: a pilot study. Clin Transl Oncol. 2016:18:1003-10.

32. Pallis $A G$, Fortpied $C$, Wedding $U$, et al. EORTC elderly task force position paper: approach to the older cancer patient. Eur J Cancer. 2010:46:1502-13.

33. Wildiers $H$, Heeren $P$, Puts $M$, et al. International Society of Geriatric Oncology consensus on geriatric assessment in older patients with cancer. J Clin Oncol. 2014;32:2595-603.

34. Sher DJ, Koshy M, Liptay MJ, et al. Influence of conformal radiotherapy technique on survival after chemoradiotherapy for patients with stage III non-small cell lung cancer in the National Cancer Data Base. Cancer. 2014; 120:2060-8.

35. Koshy $M$, Malik $R$, Spiotto $M$, et al. Association between intensity modulated radiotherapy and survival in patients with stage III 
non-small cell lung cancer treated with chemoradiotherapy. Lung Cancer. 2017;108:222-7.

36. Chun SG, Hu C, Choy H, et al. Impact of intensity-modulated radiation therapy technique for locally advanced non-small-cell lung cancer: a secondary analysis of the NRG oncology RTOG 0617 randomized clinical trial. J Clin Oncol. 2017;35:56-62.

37. University of Texas Southwestern Medical Center Clinical Trial. Hypofractionated Image-Guided Radiation Therapy (IGRT) in patients with stage II-III non-small cell lung cancer. Available from URL: https:// clinicaltrials.gov/ct2/show/NCT01459497. Accessed 16 Aug 2018.

38. Antonia SJ, Villegas A, Daniel D, et al. Durvalumab after chemoradiotherapy in stage III non-small-cell lung Cancer. N Engl J Med. 2017;377:1919-29.

Ready to submit your research? Choose BMC and benefit from:

- fast, convenient online submission

- thorough peer review by experienced researchers in your field

- rapid publication on acceptance

- support for research data, including large and complex data types

- gold Open Access which fosters wider collaboration and increased citations

- maximum visibility for your research: over $100 \mathrm{M}$ website views per year

At BMC, research is always in progress.

Learn more biomedcentral.com/submissions 